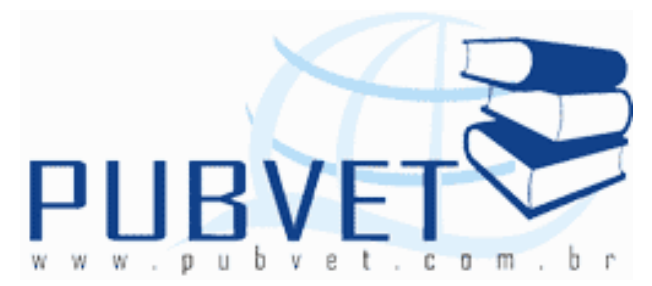

PUBVET, Publicações em Medicina Veterinária e Zootecnia.

\title{
Aceitabilidade de almôndega cozida e congelada na merenda escolar
}

Hemily Petruska da Silva Almeida ${ }^{1}$, Letícia Ríspoli Coelho ${ }^{1,2}$,Eliane Pereira Mendonça ${ }^{1,2}$, Priscila Christen Nalevaiko², Guilherme Paz Monteiro², Roberta Torres de Melo ${ }^{1,2}$, Daise Aparecida Rossi ${ }^{1,2}$

${ }^{1}$ Programa de Pós-Graduação em Medicina Veterinária da Universidade Federal de Uberlândia;

${ }^{2}$ Laboratório de Biotecnologia Animal e Aplicada da Universidade Federal de Uberlândia.

\section{Resumo}

O Programa Nacional de Alimentação Escolar é o mais antigo programa governamental na área da alimentação e nutrição, representando um importante eixo de promoção da segurança alimentar. Segundo o Fundo Nacional de Desenvolvimento da Educação é necessário realizar teste de aceitabilidade quando há inserção de novos produtos no cardápio ou para avaliar o cardápio já existente. O objetivo deste trabalho foi avaliar a aceitabilidade de almôndega cozida e congelada na merenda escolar de um município mineiro com aproximadamente 100 mil habitantes. A pesquisa de aceitação foi realizada em um estabelecimento de ensino fundamental com a participação de 171 escolares na faixa etária entre 4 e 11 anos, cursando as séries pré 1 ao quinto ano. Analisou-se a aceitação global, sabor, odor e aparência da almôndega e a possibilidade de inserção do alimento na merenda 
ALMEIDA, H.P.S. et al. Aceitabilidade de almôndega cozida e congelada na merenda escolar. PUBVET, Londrina, V. 5, N. 17, Ed. 164, Art. 1107, 2011.

escolar. Os resultados demonstraram que todos os atributos analisados estavam de acordo com o preconizado pela resolução no 38 do FNDE, que recomenda aceitação mínima de $85 \%$ para cada um dos atributos. As porcentagens de respostas favoráveis dos escolares foram: 90,64\% para aceitação global, $86,55 \%$ para sabor, $91,81 \%$ para o atributo odor, 90,58\% para o atributo aparência e $89,47 \%$ dos comensais aprovam a inserção da almôndega na alimentação escolar. Conclui-se que os testes de aceitabilidade para inserção de novos produtos na alimentação escolar é de fácil aplicação e que a almôndega cozida e congelada é um alimento com boa aceitabilidade entre os escolares.

\section{Acceptability of cooked and frozen meatballs in school lunches}

\section{Abstract}

The National School Feeding Program is the oldest government program food and nutrition, representing a major hub for the promotion of food security. According to the National Fund for Educational Development is necessary to conduct acceptance test when there is insertion of new products on the menu or evaluated the menu existing. The aim of this study was to evaluate the acceptability the meatball cooked and frozen in school meals a mining town with about 100000 habitants. The search for acceptance was performed in an elementary school, with participation of 171 students aged between 4 to 11 years, studying the 1st to the 5th series. Assessed the global acceptance, taste, smell and appearance of the meatball and the possibility of inserting the meatball in school meals. The results show that all attributes of this line with the recommended by Resolution No. 38 of the national fund for development of education, que recomenda a aceitação menor de $85 \%$ para cada um dos atributos. The percentage of favorable responses from students were: $90.64 \%$ for global acceptance, $86.55 \%$ for flavor, $91.81 \%$ for the attribute smell, $90.58 \%$ for the attribute appearance and $89.47 \%$ of diners approve the insertion of the meatball in the school meals. It is concluded that the tests of 
ALMEIDA, H.P.S. et al. Aceitabilidade de almôndega cozida e congelada na merenda escolar. PUBVET, Londrina, V. 5, N. 17, Ed. 164, Art. 1107, 2011.

acceptability for inclusion of new products in school meals is easy to apply and that the meatball cooked and frozen is a food with high acceptability among students.

\section{Introdução}

O teste de aceitabilidade com escala hedônica é uma das ferramentas da análise sensorial de alimentos, frequentemente utilizado para avaliar o grau de aceitação dos consumidores por um determinado produto, ou seja, o quanto o provador gosta ou desgosta de um produto. O teste de aceitabilidade e o teste de preferência estão inseridos no grupo de métodos sensoriais afetivos.

É necessário antes de se introduzir um alimento não conhecido a um grupo de crianças, que o mesmo seja apresentado e tenha-se previamente verificada as condições culturais e econômicas da região onde será inserido e, também, seus hábitos alimentares. A almôndega é um alimento popularmente conhecido e consumido em diversas regiões brasileiras.

De acordo com a Resolução no 38, do FNDE - Fundo Nacional de Desenvolvimento da Educação é necessário realizar teste de aceitabilidade quando há inserção de novos produtos no cardápio, ou para avaliar o cardápio já existente.

A almôndega cozida e congelada é um produto comercialmente utilizado em cozinhas industriais, ao qual possui um rendimento maior do que a carne in natura. Segundo o Padrão de Identidade e Qualidade da Almôndega (BRASIL, 2000) entende-se por almôndega o produto cárneo industrializado, obtido a partir da carne moída de uma ou mais espécies de animais, moldada na forma arredondada, adicionada de ingredientes e submetido ao processo tecnológico adequado.

As características sensoriais de sabor, aparência e odor são atributos ao qual o aluno observa e relaciona com sua expectativa em relação ao produto, estando diretamente relacionado à aceitabilidade do mesmo. A aceitabilidade de um alimento esta diretamente ligada à interação positiva entre o alimento e o aluno que o consome. 
Considerando o binômio alimento-qualidade, a avaliação sensorial tem um papel fundamental, uma vez que é utilizada como instrumento chave na seleção de produtos, na pesquisa e desenvolvimento de novos produtos, na definição do padrão de identidade e qualidade do alimento e, na avaliação da aceitação pelo consumidor.

O objetivo deste trabalho foi avaliar a aceitabilidade de almôndega cozida e congelada na merenda escolar de um município mineiro.

\section{Materiais e Métodos}

O teste de aceitabilidade foi realizado no mês de junho de 2010, na cidade de Ituiutaba, Minas Gerais, em duas escolas municipais, uma localizada na parte central da cidade e a outra na porção periférica da mesma. Os escolares que participaram do estudo possuíam faixa etária entre quatro a onze anos, identificados como série "pré um" ao quinto ano.

Para o teste foi utilizada a escala hedônica facial (escolares do $1^{\circ}$ ao $5^{\circ}$ ano) e escala hedônica mista (escolares do $4^{\circ}$ ao $5^{\circ}$ ano), ambas compostas de cinco pontos, conforme recomendações do PNAE (BRASIL, 2008).

A ficha de análise sensorial foi elaborada em conjunto com a nutricionista responsável pelo Departamento de Nutrição da Prefeitura Municipal de Ituiutaba, seguindo os parâmetros do FNDE para as mesmas.

As fichas de Análise Sensorial abordaram as seguintes perguntas:

1 ) Marque a carinha que mais represente o que você achou da "Almôndega"

2) Marque a carinha que mais represente o que você achou do sabor da "Almôndega"

3) Marque a carinha que mais represente o que você achou do odor da "Almôndega"

4) Marque a carinha que mais represente o que você achou da aparência da "Almôndega"

5) Marque a carinha que indica se você gostaria que a "Almôndega" fizesse parte da merenda escolar

Para todas as perguntas foram apresentadas figuras (Figura 1), como 
ALMEIDA, H.P.S. et al. Aceitabilidade de almôndega cozida e congelada na merenda escolar. PUBVET, Londrina, V. 5, N. 17, Ed. 164, Art. 1107, 2011.

preconizado pela resolução no 38 (BRASIL, 2009). Atribui-se as seguintes pontuações e atribuições para as carinhas: (1) desgostei extremamente, (2) desgostei moderadamente, (3) indiferente, (4) gostei moderadamente e (5) gostei extremamente.

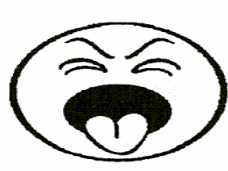

(1)

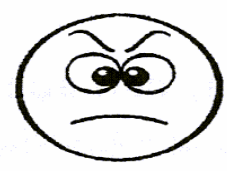

(2)

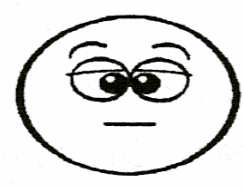

(3)

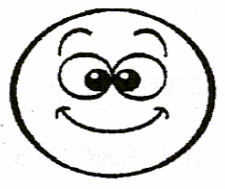

(4)

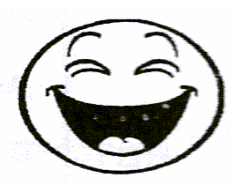

(5)

Figura 1. Ficha de análise sensorial de cinco pontos apresentadas aos escolares para avaliação da aceitabilidade de almôndega cozida e congelada na merenda escolar de um município mineiro.

\section{Matéria - prima}

A Almôndega Cozida e Congelada foi fornecida por uma empresa do ramo frigorífico, sob Serviço de Inspeção Federal (SIF). O alimento é produzido no complexo Industrial situada na cidade de Lins /SP.

O lote de almôndegas utilizado para o teste foi previamente analisado em Laboratório do governo de São Paulo, credenciado sob o número RE 1144. Quanto à inocuidade microbiológica e matérias microscópicas e microscópicas prejudiciais à saúde foram atendidos os padrões descritos na Resolução 12 da ANVISA (BRASIL, 2001) e Resolução 175 da ANVISA (BRASIL, 2003), respectivamente. No mesmo laboratório foi estabelecido que o alimento era composto $(\mathrm{g} / 100 \mathrm{~g})$ de: 2,56 de açúcares totais, 1,81 de amido, 10,74 de gordura e $11,59 \mathrm{~g}$ de proteínas. Cálcio na base seca, nitrato expresso em nitrito de sódio apresentaram concentrações de $62,964 \mathrm{mg} / 100 \mathrm{~g}$ e 12,69 mg/kg, respectivamente. 
ALMEIDA, H.P.S. et al. Aceitabilidade de almôndega cozida e congelada na merenda escolar. PUBVET, Londrina, V. 5, N. 17, Ed. 164, Art. 1107, 2011.

\section{Preparação da Almôndega}

As almôndegas congeladas foram transportadas à escola em caixa térmica. Para o teste, foram preparadas pela cozinheira, nos estabelecimentos, do mesmo modo como seria servida na rotina das duas escolas municipais, conforme recomenda a resolução n038 do FNDE (BRASIL, 2009), A Figura 2 ilustra os procedimentos da cozinheira para o preparo da almôndega servida aos comensais.

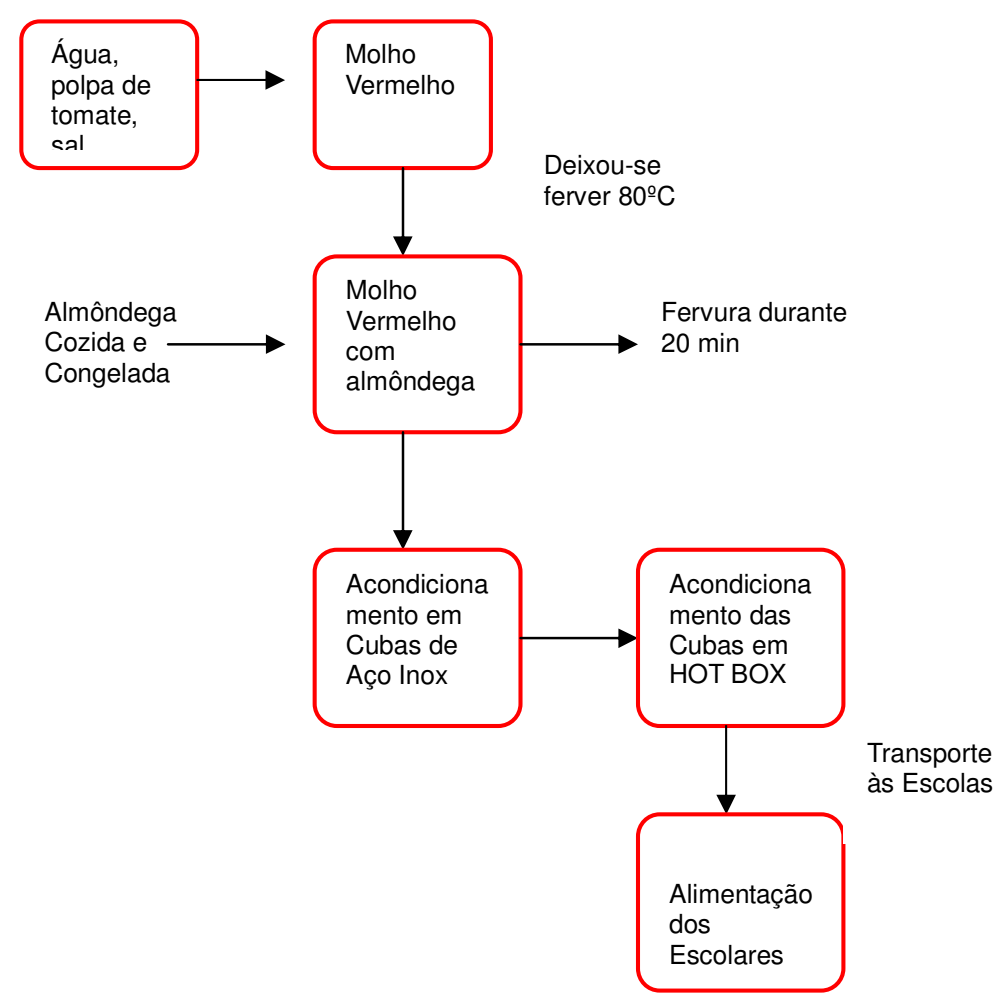

Figura 2. Fluxograma preparação da almôndega

A preparação do cardápio foi realizada normalmente, apenas substituiuse a carne do dia pela almôndega cozida e congelada. Os escolares degustaram as almôndegas acompanhadas das guarnições arroz e salada, como em sua alimentação escolar diária, sendo a quantidade servida de duas almôndegas (40 g).

Os escolares responderam ao questionário (escala hedônica facial ou 
ALMEIDA, H.P.S. et al. Aceitabilidade de almôndega cozida e congelada na merenda escolar. PUBVET, Londrina, V. 5, N. 17, Ed. 164, Art. 1107, 2011.

escala hedônica fácil mista), adicionando a cada ficha: nome, série escolar, idade e data. Houve explanação prévia pela nutricionista, de como preencher as fichas de analise sensorial. Os alunos de quatro e cinco anos tiveram auxilio das professoras para o preenchimento do questionário, já os alunos com idades entre seis a onze anos preencheram o questionário individualmente. As fichas foram submetidas aos escolares em sala de aula após o consumo da almôndega, como preconiza a resolução no 38 do FNDE (BRASIL, 2009), mantendo um ambiente individual.

\section{Análise Estatística}

O experimento contou com 171 provadores não treinados. O mesmo foi realizado em um único dia sem repetições.

Foram utilizados 70 provadores com quatro anos de idade, 23 provadores com cinco anos de idade, 19 provadores com seis anos de idade, 12 provadores com sete anos de idade, 15 provadores com oito anos de idade, 14 provadores com nove anos de idade, 9 provadores com 10 anos de idade e 9 provadores com 11 anos.

Os resultados foram tabulados e avaliados através de estatística descritiva, utilizando-se o programa estatístico SISVAR 4.6 (FERREIRA, 2004).

\section{Resultados e Discussão}

Os resultados obtidos com o teste de aceitabilidade para almôndega cozida e congelada demonstrou que esse alimento pode ser uma alternativa viável com boa aceitabilidade de inserção na merenda escolar de escolas do município de Ituiutaba.

As médias gerais obtidas para cada um dos atributos testados foram entre 4,4 e 4,5, que correspondem às características de "gostei moderadamente" e "gostei extremamente", respectivamente (Figura 3). 
ALMEIDA, H.P.S. et al. Aceitabilidade de almôndega cozida e congelada na merenda escolar. PUBVET, Londrina, V. 5, N. 17, Ed. 164, Art. 1107, 2011.

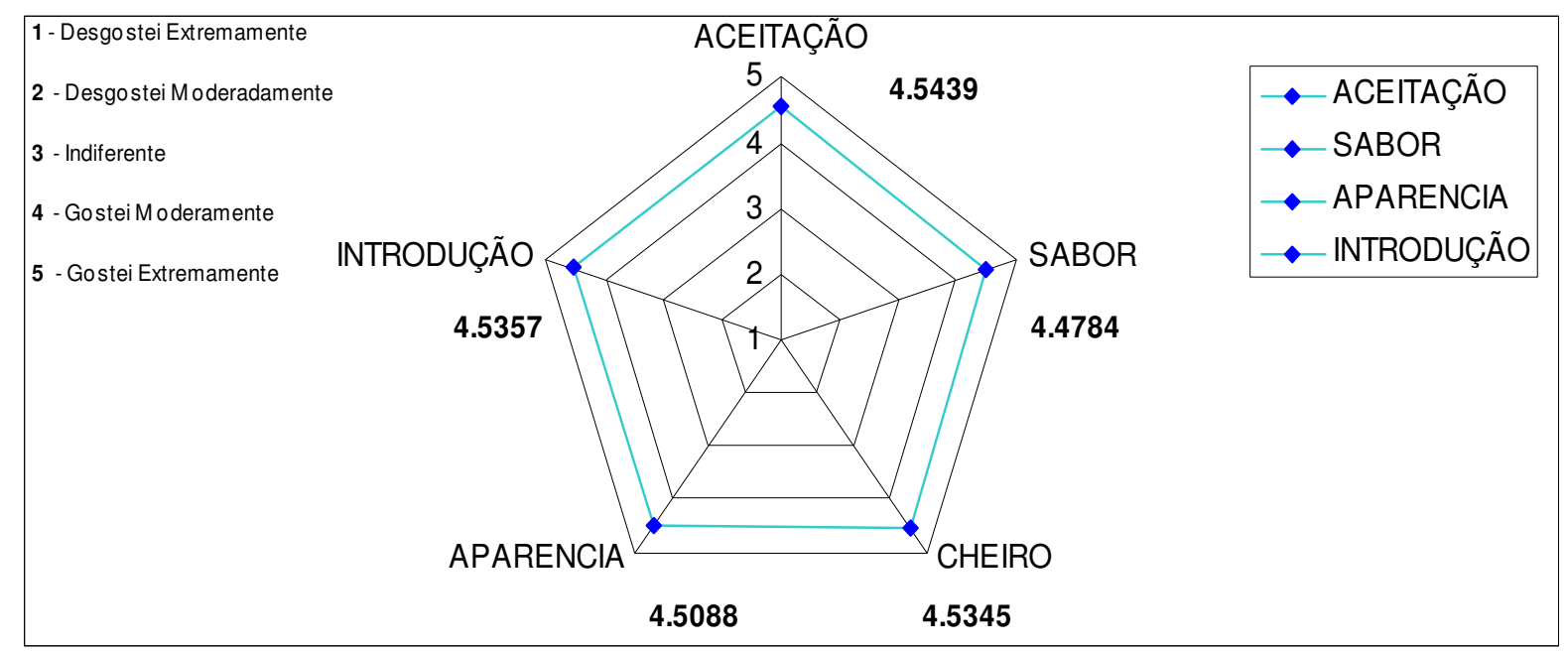

Figura 3. Gráfico radar das médias obtidas para cada atributo.

A indagação "Marque a carinha que mais represente o que você achou da Almôndega" reflete a aceitação global dos escolares (Figura 4). Das respostas obtidas dos 171 alunos, gostei extremamente (nota 5) foi a opção de 78,95\% (135) alunos, seguido de $11,69 \%$ (20) que responderam gostei moderadamente (nota 4). Estas duas opções totalizaram 90,64\% (155) das respostas obtidas. Dos $16(9,36 \%)$ alunos restantes, $1,17 \%$ (2) atribuíram nota 3 (Indiferente), outros dois $(1,17 \%)$ marcaram a opção desgostei moderadamente (nota 2) e desgostei extremamente (nota 1) foi marcada por por 12 alunos (7,2\%). Estes resultados estão na Figura 4. 


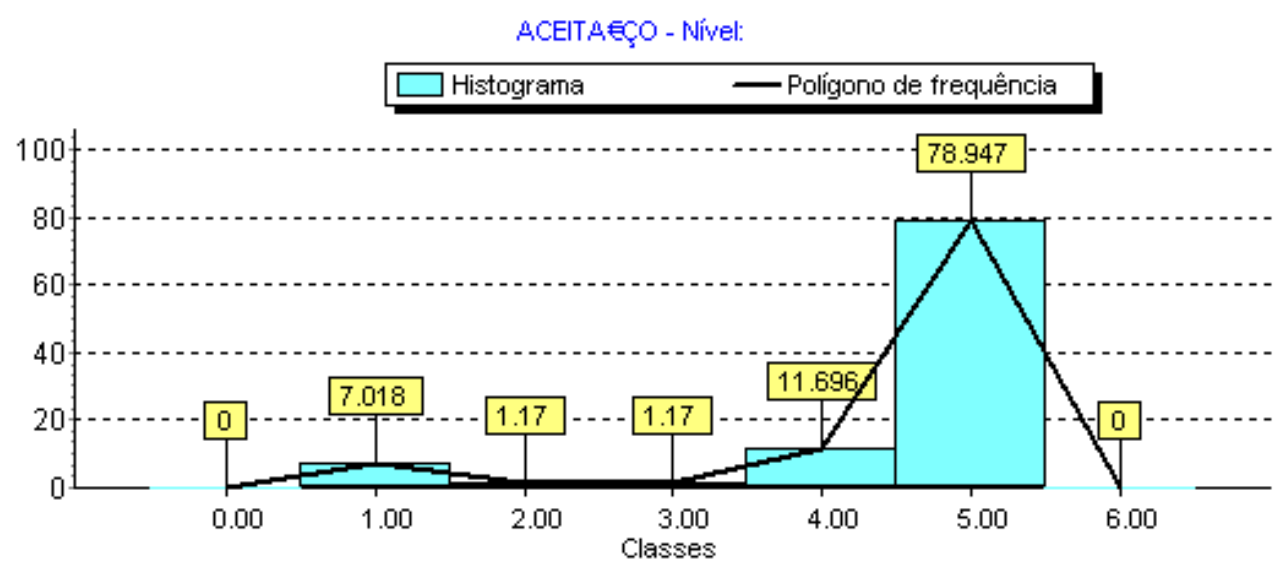

Figura 4 - Aceitação global da almôndega. Notas atribuídas pelos comensais (\%): nota 1 - desgostei extremamente; nota 2 - desgostei moderadamente; nota 3 - indiferente; nota 4 - gostei moderadamente; nota 5 - gostei extremamente.

O anexo VIII da resolução 38 (BRASIL, 2009), traz que: Para o cálculo do índice de aceitabilidade, será considerada a somatória das porcentagens de respostas dadas as "carinhas" gostei (4) e adorei (5). Assim, para o calculo do índice de aceitabilidade foi utilizado a somatória das porcentagens das repostas gostei moderadamente e gostei extremamente, que correspondem às notas 4 e 5 , respectivamente.

Os resultados obtidos para o segundo atributo, relacionado ao sabor, respondido na indagação "Marque a carinha que mais represente o que você achou do sabor da almôndega pode ser visualizado na Figura 5. A aceitação do alimento, correspondente ao somatório notas 4 e 5 , de gostei moderadamente e gostei extremamente foi a resposta de $86,55 \%$ (148/171) alunos, estando acima do nível de aceitação preconizado pela Resolução nº 38 (BRASIL, 2009) que é de $85 \%$. Onze alunos $(6,43 \%)$ atribuíram a nota 3 de indiferente, quatro (2,33\%) atribuíram a nota 2 de desgostei moderadamente e oito alunos $(4,67 \%)$ atribuíram a nota 1 , de desgostei extremamente para o sabor da almôndega. 


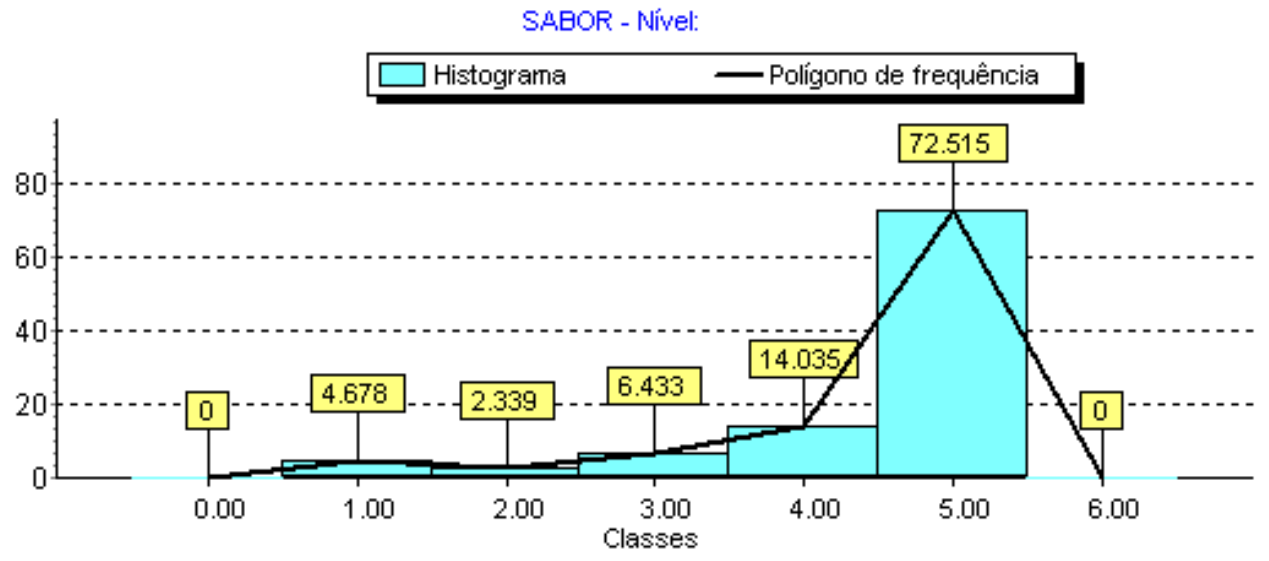

Figura 5 - Sabor da almôndega. Notas atribuídas pelos comensais (\%): nota 1 - desgostei extremamente; nota 2 - desgostei moderadamente; nota 3 indiferente; nota 4 - gostei moderadamente; nota 5 - gostei extremamente.

Na Figura 6 pode-se observar a percepção dos escolares referente ao atributo odor da almôndega. Este atributo foi à resposta ao questionamento "Marque a carinha que mais represente o que você achou do odor da "Almôndega". Os resultados obtidos para este atributo foi semelhante aos obtidos para a aceitação global, com $157(91,81 \%)$ dos escolares aprovando o odor e atribuindo notas $4(20,46 \%)$ e $5(71,34 \%)$. Dos 14 alunos restantes $(8,19 \%), 4$ atribuíram nota 3 sendo indiferente ao cheiro da almôndega, um $(0,58 \%)$ atribuiu nota 4, e $(5,26 \%)$ dos comensais desgostaram extremamente do odor da almôndega. 
ALMEIDA, H.P.S. et al. Aceitabilidade de almôndega cozida e congelada na merenda escolar. PUBVET, Londrina, V. 5, N. 17, Ed. 164, Art. 1107, 2011.

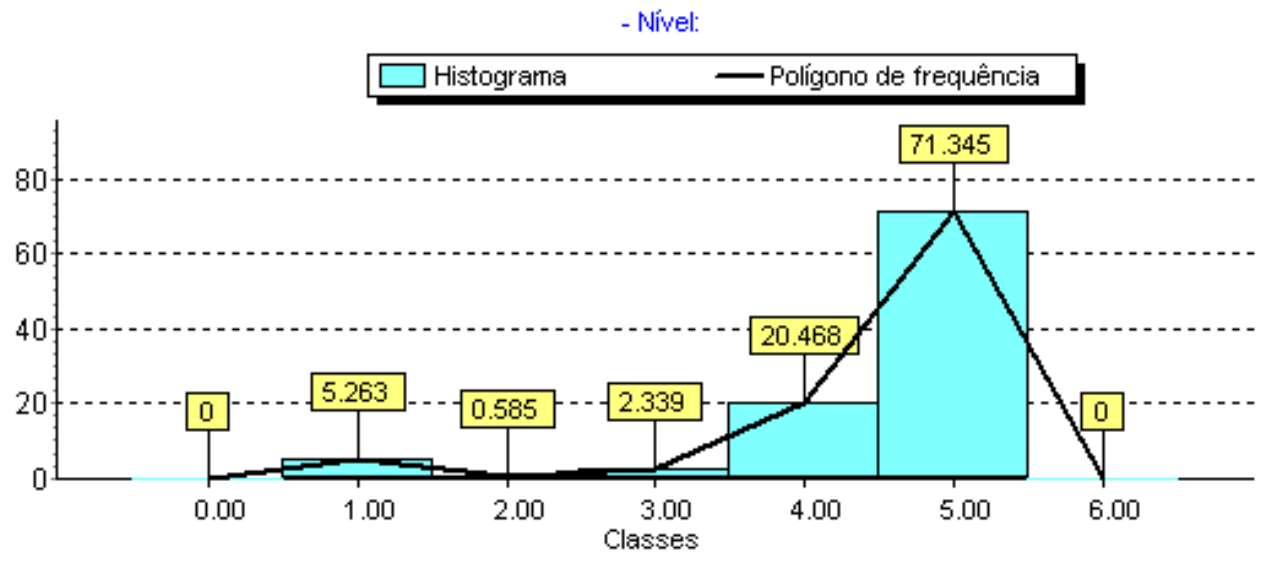

Figura 6 - Odor da almôndega. Notas atribuídas pelos comensais (\%): nota 1 - desgostei extremamente; nota 2 - desgostei moderadamente; nota 3 indiferente; nota 4 - gostei moderadamente; nota 5 - gostei extremamente.

Para a aparência, 154/171 (90,58\%) escolares responderam a este atributo com notas 4 e 5 (Figura 7). Como a primeira avaliação do alimento é feita com os olhos, ou seja, pela aparência, cor, forma, tamanho, brilho e características da superfície, este atributo constitui o primeiro critério de aprovação do produto testado (SÃO PAULO, 2008).

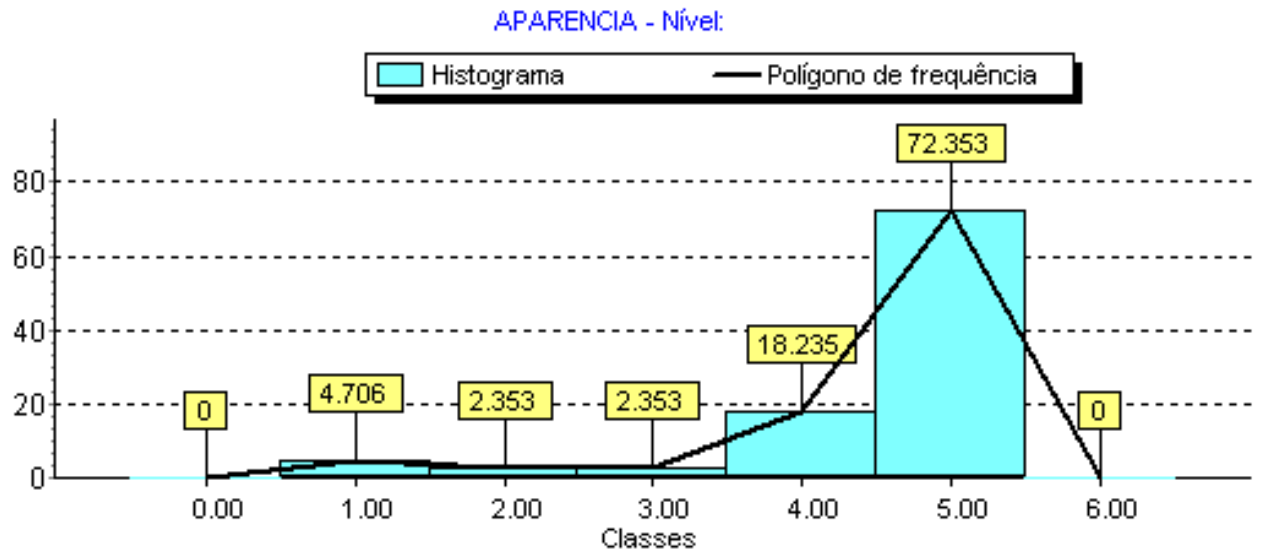

Figura 7 - Aparência da almôndega. Notas atribuídas pelos comensais (\%): nota 1 - desgostei extremamente; nota 2 - desgostei moderadamente; nota 3 - indiferente; nota 4 - gostei moderadamente; nota 5 - gostei extremamente. 
ALMEIDA, H.P.S. et al. Aceitabilidade de almôndega cozida e congelada na merenda escolar. PUBVET, Londrina, V. 5, N. 17, Ed. 164, Art. 1107, 2011.

Na Figura 8 estão demonstradas as respostas dos escolares quando perguntados se gostariam que a almôndega fizesse parte da alimentação escolar. Os resultados correspondentes às notas 4 e 5 foi a opção de $89,47 \%$ (153/171) alunos, mostrando que a aceitabilidade para inserção da almôndega na merenda escolar foi acima do preconizado pelo FNDE, que é de $85 \%$.

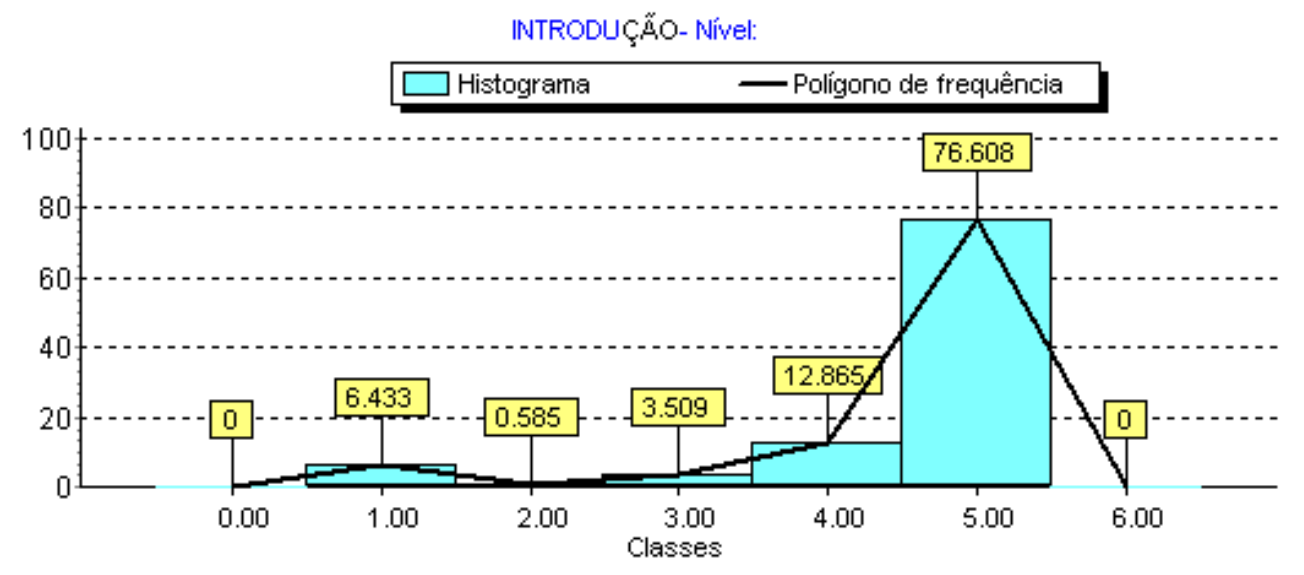

Figura 8 - Inserção da almôndega na merenda escolar. Notas atribuídas pelos comensais (\%) ao atributo aceitação da introdução da almôndega na merenda escolar. Nota 1 -Atributo Desgostei extremamente, Nota 2 -Atributo desgostei moderadamente, nota 3 - Atributo Indiferente, nota 4 - Atributo Gostei moderadamente, nota 5 - Atributo Gostei extremamente.

Segundo a resolução 38 do PNAE (BRASIL, 2009), o índice de aceitabilidade para um alimento com o uso da escala hedônica, deve ser de, no mínimo, $85 \%$. Todos os atributos testados neste estudo: odor, sabor, aparência, aceitação global e inserção da almôndega na merenda escolar, mostraram taxas acima do preconizado, demonstrando a aceitação do alimento em estudo (almôndega) pelos comensais.

Em um trabalho realizado por Teo et al. (2009) na cidade de Chapecó (SC), analisando a aceitação, adesão e condições de distribuição da alimentação na escola, encontrou-se um índice de aceitação global de 70,8\%, semelhante ao relatado por Martins et al. (2004) em Piracicaba (SP), para alimentos servidos comumente na merenda escolar (arroz, feijão ,salada e 
ALMEIDA, H.P.S. et al. Aceitabilidade de almôndega cozida e congelada na merenda escolar. PUBVET, Londrina, V. 5, N. 17, Ed. 164, Art. 1107, 2011.

prato protéico). Os autores pesquisaram o índice geral de aceitação da alimentação escolar oferecida em escolas da rede municipal e estadual investigaram a aceitação da alimentação escolar em Piracicaba (SP), observaram que era de $67,0 \%$, abaixo do mínimo preconizado pela legislação (BRASIL, 2009), mostrando que a falta de variedade no cardápio das escolas e a repetição dos mesmos pode causar a insatisfação parcial dos alunos, diminuindo assim a aceitabilidade global da alimentação servida. Resultados mais próximos aos preconizados para a aceitação da alimentação escolar foram encontrados por Sturion et al. (2005) e Muniz e Carvalho (2007) em João Pessoa (PB), de 85,0\% e 82,0\%, respectivamente na mesma linha de pesquisa de aceitação geral da alimentação servida usualmente, demonstrando a necessidade de estudos para verificação de aceitabilidade na merenda escolar.

\section{Conclusões}

O teste de aceitabilidade como ferramenta de avaliação para a introdução de um novo produto na alimentação escolar mostrou-se de fácil execução. Os resultados obtidos para a aceitabilidade da almôndega cozida congelada no cardápio mostrou que este alimento teve aceitabilidade acima de $85 \%$, atendendo as exigências da legislação vigente. Os atributos de cheiro e aceitação global superou $90 \%$ de aceitação.

A obrigatoriedade de execução de um teste de aceitabilidade para novos alimentos é uma boa iniciativa, garantindo que a inserção será bem aceita pelos escolares e contribui para o hábito do consumo da merenda escolar.

\section{Referências}

AGENCIA NACIONAL DE VIGILÂNCIA SANITARIA - ANVISA.Resolução - RDC no 175, de 8 de julho de 2003.Regulamento Técnico de Avaliação de Matérias Macroscópicas e Microscópicas Prejudiciais à Saúde Humana em Alimentos Embalados. Diário Oficial da União - Seção 1, no 130, ISSN 1677 - 7042, p: 32-33.

BRASIL. Fundo Nacional de Desenvolvimento da Educação. Histórico da Alimentação Escolar, Brasília. Disponível em: < http:// www. fnde.gov.br>. Acesso em: 17 nov. 2010. 
BRASIL. Fundo Nacional de Desenvolvimento da Educação. Relatório do Grupo de Trabalho: Aplicabilidade do teste de aceitabilidade nos alimentos destinados ao Programa Nacional de Alimentação Escolar. Brasília, junho. 2009.

BRASIL. Ministério da Agricultura. Regulamento Técnico de Identidade e Qualidade de Almôndega, de Apresuntado, de Fiambre, de Hambúrguer, de Quibe, de Presunto Cozido. Diário Oficial, Brasília, no 149, seção 1, p. 7-12, 2000.

BRASIL. Resolução FNDE/CD/No 38 /2009. Dispõe sobre o atendimento da alimentação escolar aos alunos da educação básica no Programa Nacional de Alimentação Escolar - PNAE, 2009.

BRASIL.Resolução DC/ANVISA no 12, de 2001.Aprova o regulamento técnico sobre padrões microbiológicos para alimentos.Diário Oficial da União, Brasília, DF, Seção 01, p.54, jan.2001.

CHAVES, L. G.; BRITO, R. R.; TEIXEIRA, R. M.; MUSTAFA, V. S. Programa Nacional de Alimentação Escolar: compromisso com a saúde pública. Nutr. Prof., v. 3, n. 12, p. 2227, 2007.

FERREIRA, D.F. SISVAR - versão 4.6. Lavras: DEX/UFLA, 2004. 32p.

MARTINS, R. C. B.; et al. Aceitabilidade da Alimentação Escolar no Ensino Público Fundamental. Saúde em Revista, Piracicaba, v. 6, n 13, p. 71-78, 2004.

MUNIZ, V. M.; CARVALHO, A. T. O Programa Nacional de Alimentação Escolar em município do estado da Paraíba: um estudo sob o olhar dos beneficiários do Programa. Rev. Nutr., v. 20, n. 3,p. 285-296, 2007.

SÃO PAULO. Analise Sensorial. Departamento de Merenda Escolar do Estado de São Paulo. 2008.

STURION, G. L.; SILVA, M. V.; OMETTO, A. M. H.; FURTUOSO, M. C. O.; PIPITONE, M. A. P. Fatores condicionantes da adesão dos alunos ao Programa de Alimentação Escolar no Brasil. Rev. Nutr., v. 18, n. 2, p. 167-181, 2005.

SPINELLI, M. A. S; CANESQUI, A. M. Programa de alimentação escolar no estado de Mato Grosso: da centralização à descentralização (1979 - 1995). Revista de Nutrição, v. 15, n० 1, p. 105-117, 2002.

STEFANINI, M. L. R. Merenda escolar: História, Evolução e Contribuição no atendimento das necessidades nutricionais da criança. São Paulo, 1997.

TEO, C. R. P. A.; CORRÊA, E. N.; GALLINA, L. S., FRANSOZI, C. Programa nacional de alimentação escolar: adesão, aceitação e condições de distribuição de alimentação na escola. Nutrire: rev. Soc. Bras. Alim. Nutr. = J. Brazilian Soc. Food Nutr., São Paulo, SP,v. 34, n. 3, p. 165-185, dez. 2009. 